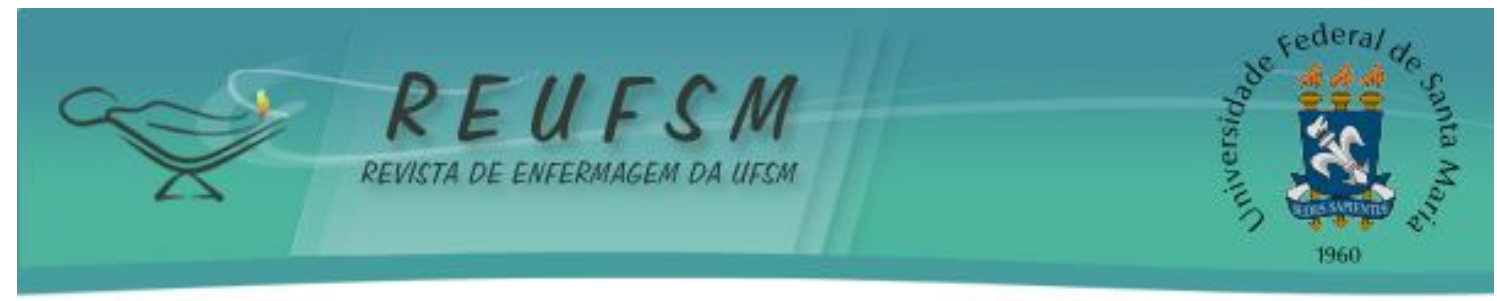

ARTIGO ORIGINAL

\title{
A GÍRIA: A COMUNICAÇÃO DE ADOLESCENTES USUÁRIOS DE SUBSTÂNCIAS PSICOATIVAS ${ }^{1}$ \\ SLANG: THE COMMUNICATION OF ADOLESCENTS USERS OF PSYCHOACTIVE SUBST ANCES ARGOT: LA COMUNICACIÓN DE LOS ADOLESCENTES USUARIOS DE SUST ANCIAS PSICOACTIVAS
}

Zaléia Prado de Brum ${ }^{1}$ Débora Schlotefeldt Siniak²

RESUMO: 0 estudo teve como objetivo compreender a comunicação utilizada pelos adolescentes, usuários de substâncias psicoativas (SPA) através da decodificação do tipo de linguagem adotada por eles. Pesquisa qualitativa, descritiva, realizada com adolescentes do sexo masculino, residentes em uma comunidade terapêutica do interior do RS, em fevereiro de 2010. Os dados foram coletados por meio de Grupo Focal. A análise dos resultados ocorreu por meio da Análise de Conteúdo, originando as categorias temáticas: designação de pessoa, expressão de sentimento, termos dados a objetos e situações, codinomes dados as SPA, termos originários do código penal. Os dados sinalizaram que a gíria utilizada pelos adolescentes faz-se um recurso importante, principalmente para expressar sentimentos como ironia, desprezo, humor, crítica, dentre outros. Conclui-se que este estudo trouxe uma melhor compreensão sobre a comunicação utilizada entre os adolescentes em seu cotidiano e o quanto isto contribui para o cuidado de enfermagem e na promoção da saúde.

Descritores: Adolescente; Vulnerabilidade; Comunicação; Promoção da saúde.

ABSTRACT: This study aimed to understand the communication used by adolescents, psychoactive substance users (PAS) by decoding the type of language adopted by them. Qualitative, descriptive research, conducted with young male living in a therapeutic community in the interior of the RS, in february 2010. Data were collected through Focus Group. The results came through content analysis, resulting in the thematic categories: name of person, expression of feeling, terms to objects and situations, codenames to drugs code. The data indicate that the slang used by teenagers is an important resource, especially to express feelings such as irony, contempt, humor, criticism, among others. It is concluded that this study brought a better understanding of communication used among teens in their daily lives and how this contributes to the nursing care and health promotion.

Descriptors: Adolescent; Vulnerability; Comunication; Health promotion.

RESUMEN: El estudio tuvo como objetivo comprender la comunicación utilizada por los adolescentes, usuarios de sustancias psicoactivas (SPA) mediante la decodificación del tipo de lenguaje que ellos adoptaron. Pesquisa cualitativa, descriptiva, realizada con adolescentes del sexo masculino, residentes en una comunidad terapéutica en el interior del RS, en febrero de 2010. Los datos fueron recolectados a través del Grupo de Enfoque. Los resultados se dieron a través de análisis de contenido, dando lugar a las categorías temáticas: designación de la persona, la expresión de los sentimientos, termos dados a los

\footnotetext{
${ }^{1}$ Artigo elaborado a partir do Trabalho de Conclusão de Curso apresentado a Universidade Regional Integrada do Alto Uruguai e das Missões.

${ }^{1}$ Enfermeira. Mestre em Enfermagem. Docente do Curso de Enfermagem da Universidade Regional Integrada do Alto Uruguai e das Missões - Campus Santo Ângelo/ RS. Membro do GEPESE. E-mail: zaleia@urisan.tche.br

2 Enfermeira. Graduação pela Universidade Regional Integrada do Alto Uruguai e das Missões / 2011 - Campus Santo Ângelo/RS. Membro do Grupo de Estudos e Pesquisas em Enfermagem Saúde e Educação- GEPESE. Email: debynha33@hotmail.com
} 


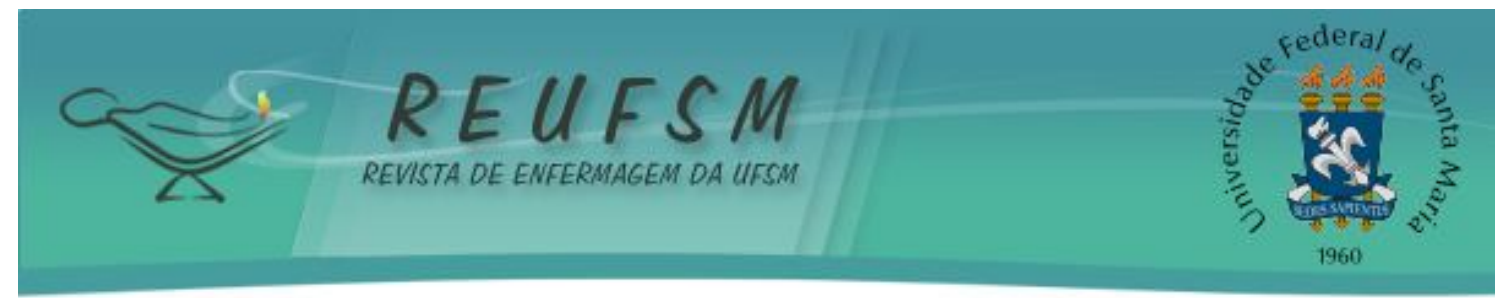

objetos y las situaciones, nombres dados a las SPA, los termos originarios del código penal. Los datos indican que la argot utilizada por los adolescentes es un recurso importante, sobre todo para expresar sentimientos tales como la ironía, el desprecio, el humor, la crítica, entre otros. Por lo tanto se concluye que este estudio permitió una mejor comprensión de la comunicación utilizado entre los adolescentes en su vida cotidiana y cómo esto contribuye en la atención de enfermería y promoción de la salud.

Descriptores: Adolescente; Vulnerabilidad; Comunicación; Promoción de la salud.

\section{INTRODUÇÃO}

A dependência química é considerada um problema de saúde pública e o aumento do consumo entre os adolescentes é cada vez mais preocupante, gerando consequências diretas na qualidade de vida dos indivíduos, acarretando inúmeros riscos e levando os usuários a uma situação de vulnerabilidade. Esta pode ser definida como "estado de pessoas ou grupos que, por quaisquer razões ou motivos, tenham a sua capacidade de autodeterminação reduzida". ${ }^{1}$

No presente estudo, o grupo de pessoas ao qual nos referimos são os adolescentes que, de acordo com o Estatuto da Criança e Adolescente (ECA), caracterizam-se como aqueles que possuem idade entre doze e dezoito anos. ${ }^{2}$

0 papel da linguagem é fundamental nas relações entre os seres humanos, neste caso os adolescentes, considerando-se que qualquer sociedade depende desta para a construção da interação social entre os indivíduos. A comunicação humana pode efetivar-se por meio da linguagem verbal ou através da linguagem não-verbal, sendo estas convenções variáveis de acordo com as necessidades e interesses de cada grupo social, podendo ser agrupadas em conjuntos conhecidos como códigos. ${ }^{3}$ Podemos entender a língua como um código que está em contínua mudança, permitindo uma multiplicidade de usos dependendo das diversas situações comunicacionais em que os falantes se encontrem. ${ }^{4}$

A associação entre língua e sociedade é estudada pela sociolinguística. Dentre as formas de variação de linguagem pode ser citada a "gíria que é abordada como um termo genérico usado para designar o fenômeno sociolingüístico no qual grupos sociais formam um vocábulo próprio". ${ }^{5}$ Este tipo de linguagem faz-se presente no cotidiano de um grupo de pessoas, seja dentro da família, na escola, no trabalho, no lazer, dentre outros segmentos da sociedade. Dessa forma, ela mantém a identidade de um determinado grupo social.

Sob esse prisma, podemos dizer que cada grupo cria uma linguagem especial, uma espécie de código linguístico que se diferencia de outros grupos, formando uma língua diferente dentro de uma língua já existente tendo, assim, léxico, semântica e morfologia próprias e, ao mesmo tempo, semelhantes aos da língua comum.

A gíria não é uma linguagem independente, mas uma forma parasitária da língua, a qual utiliza mesmos os processos de criação da língua comum. Ao observar a maneira de um indivíduo falar, podemos não só identificar seu estilo, mas também relacioná-lo com determinados grupos. ${ }^{6}$

Historicamente foi sendo construído preconceito no uso da gíria, enquanto forma de linguagem, pois ela "foi marginalizada pela sociedade, sendo usada apenas por presidiários, drogados, prostitutas, homossexuais e outros grupos que eram rejeitados e mal vistos perante a sociedade". ${ }^{7}$

Porém, com o passar dos anos, a gíria foi conquistando espaço e sendo aceita pela sociedade como afirmam alguns autores. A gíria está presente no cotidiano da vida dos membros de uma sociedade em seus diversos setores e devido à presença da linguagem gíria no dia-a-dia e a uma nova concepção de língua que envolve variações, a gíria passou a 


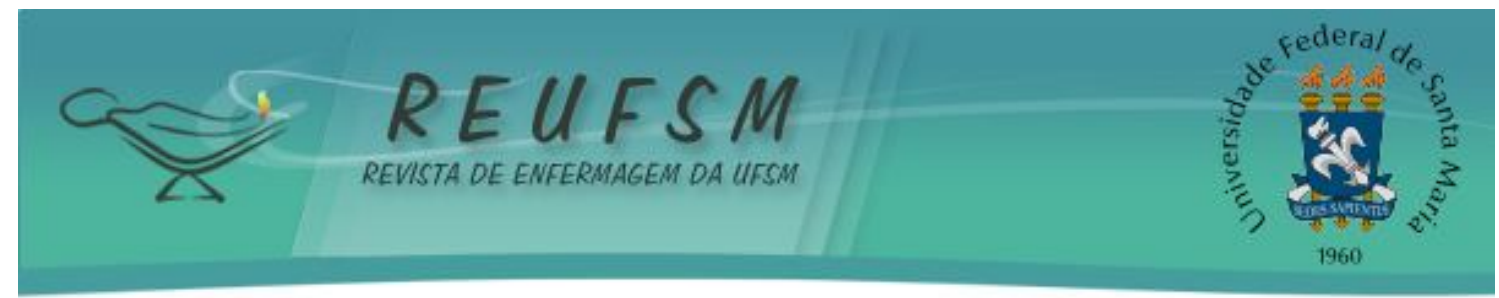

ser tratada, não mais como algo errado, de forma preconceituosa, mas como uma maneira diferenciada de expressão, adequada a situações especiais. ${ }^{5}$

Após vencer o preconceito linguístico, a gíria se firmou entre os falantes e proporcionou a edificação gramatical da nossa língua. 0 vocabulário de um determinado grupo manifesta-se no léxico da língua, operada pelos falantes que por ela articulam as suas idéias e pensamentos e seu uso contínuo propicia gramaticalmente um enriquecimento, renovação e evolução progressiva da linguagem e da língua. ${ }^{7}$

O processo de construção da identidade dá-se a partir da relação entre indivíduo e grupo. Além das relações grupais e fatores inatos, características adquiridas da personalidade do próprio indivíduo e de fatores interpessoais, fazem parte da construção da identidade cultural do mesmo. ${ }^{8}$

A identidade cultural é uma forma de identidade coletiva que é característica de um grupo social. Ela se fixa como uma construção social estabelecida e faz os indivíduos se sentirem mais próximos e semelhantes. ${ }^{9}$

Sendo assim, justificamos este estudo em virtude da necessidade de compreender as formas de comunicação utilizadas pelos adolescentes usuários de substâncias psicoativas (SPA), para que possamos melhor planejar e desenvolver as ações de enfermagem.

Desse modo, elaboramos a seguinte questão de pesquisa: quais as gírias utilizadas pelos adolescentes usuários de substâncias psicoativas e qual o seu significado? Tendo como objetivo compreender a comunicação utilizada pelos adolescentes, usuários de substâncias psicoativas através da decodificação do tipo de linguagem adotada por eles.

\section{MÉTODO}

Trata-se de uma pesquisa qualitativa, descritiva realizada em uma comunidade terapêutica de um município da região Noroeste do estado do Rio Grande do Sul, no mês de fevereiro de 2010 no qual participaram um grupo composto por 12 adolescentes do sexo masculino, residentes da instituição escolhida no período de estudo, usuários de SPA, com faixa etária entre 12 e 18 anos. A Comunidade Terapêutica é um ambiente para a recuperação psicossocial por meio do convívio do dependente químico com outras pessoas que possuem 0 mesmo problema. ${ }^{10}$ Inicialmente, os adolescentes foram convidados a participarem da pesquisa, os quais aceitaram de maneira esclarecida. Vale salientar que não houve critério de discriminação quanto à raça, grau de ensino ou poder socioeconômico. Sendo assim, foram respeitados os aspectos éticos conforme a Resolução № 196/96 do Conselho Nacional de Saúde $^{1}$ a qual regulamenta a pesquisa com seres humanos. Para tanto, o Protocolo do Projeto de Pesquisa foi aprovado pelo Comitê de Ética em Pesquisa da Universidade no dia 12/ 01/2010, sob o № 003-4/ PPH/ 10.

Nesta perspectiva, o estudo mostra o universo de significados, na decodificação da fala e dos gestos dos suj eitos, pois "os pesquisadores qualitativistas estudam as coisas em seu contexto natural, tentando dar sentido ou interpretar fenômenos nos termos das significações que as pessoas trazem para estes". ${ }^{11}$ Sendo assim, como pesquisadores buscamos "descrever as particularidades de determinada população ou fenômeno ou o estabelecimento de relações entre variáveis. Assume, em geral, a forma de levantamento". ${ }^{12}$

A técnica escolhida para a coleta de dados foi através do Grupo Focal o qual "consiste na interação entre os participantes e o pesquisador, que objetiva colher dados a partir da discussão focada em tópicos específicos e diretivos". ${ }^{13}$ Também, utilizou-se a observação participante que "consiste na inserção do pesquisador no interior do grupo observado, interagindo por longos períodos com os suj eitos, buscando partilhar o seu cotidiano". ${ }^{14}$

Para a realização do Grupo Focal, os adolescentes participantes foram escolhidos de forma aleatória, sendo todos homogêneos, com níveis sócioeconômicos e culturais 


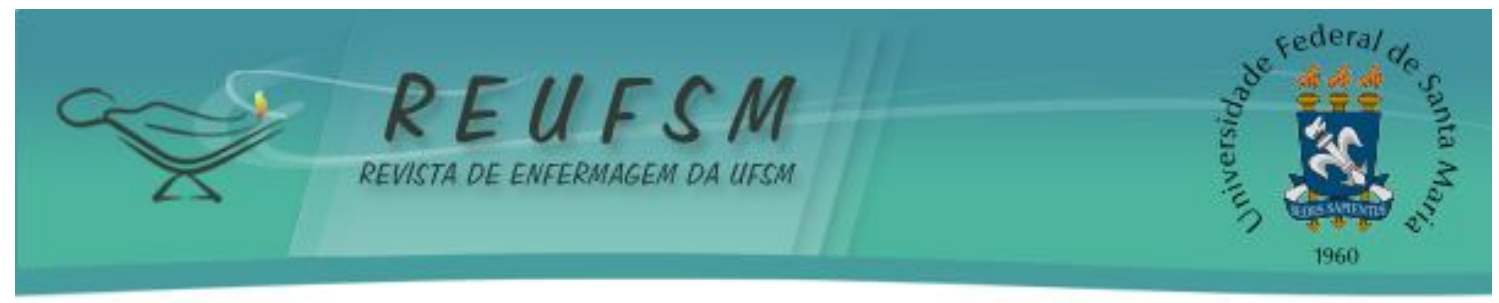

semelhantes, todos el es residentes em uma comunidade terapêutica para tratamento do uso de substância psicoativa. Essa técnica constituiu em buscar informações individuais, bem como as do grupal. No momento da realização do Grupo Focal, todos estiveram reunidos em torno do interesse relacionado à comunicação. A investigadora formou o grupo a partir da informação do seu objetivo obtendo consentimento dos participantes para anotar os depoimentos. A fim de ter uma melhor compreensão da linguagem verbal, foi necessária a observação das expressões corporais, faciais, das mãos e até mesmo do olhar, pois esse tipo de comunicação facilitou nossa compreensão do contexto léxico das palavras. Os dados obtidos foram usados para referir exatamente o que disseram, sendo que a percepção do observador sobre a linguagem não verbal foi validada pelo grupo. 0 Grupo Focal foi conduzido por um mediador através de uma discussão informal, o qual deixou explícito o tema a ser abordado e o objetivo do encontro. Além disso, foi incentivada a participação e a interação dos adolescentes, de modo que todos pudessem discorrer sobre o tema, dando suas opiniões e, assim, gerando debate entre os participantes do grupo. Os achados foram anotados pela observadora, a qual registrava as informações verbais e não verbais emitidas pelos participantes. 0 grupo teve duração de aproximadamente 60 minutos e foi realizado na instituição escolhida, em um ambiente reservado para que não houvesse intervenções no transcorrer da coleta.

0 número de grupos foi de acordo com o alcance do objetivo do estudo, pois a interação da investigadora e observadora, respectivamente como bolsista e enfermeira, ajudou para que todos ficassem à vontade e o diálogo e a observação fluíssem de forma tranqüila, não havendo necessidade de realização de outros encontros, devido à saturação dos depoimentos ter ocorrido já no primeiro encontro. A partir do objetivo, apresentamos como questão: quais as gírias usadas por eles no cotidiano e seus significados? A partir daí, sistematizamos e organizamos através de categorização temática por saturação das falas.

Após a realização do grupo focal, os dados foram transcritos e analisados. Tanto para a análise da comunicação verbal como da não verbal foi utilizado a análise de conteúdo temática, a qual visa descobrir os núcleos de sentido de uma comunicação, onde a presença ou frequência devem significar alguma coisa para o objetivo analítico visado. ${ }^{15}$ A análise conduziu à construção de cinco categorias: designação de pessoa, expressão de sentimento, termos dados a objetos e situações, codinomes dados as substâncias psicoativas (SPA) e termos originários do código penal.

\section{ANÁLISE E DISCUSSÃO DOS RESULTADOS}

\section{Designação de pessoa}

A gíria "dos meus" é empregada para designar amigo e "mano" é usado para definir um amigo que é tido como um irmão. Os vocábulos " $X 9$ " e "caquete" referem-se a uma pessoa que é "fofoqueira". "Traíra" segundo o grupo é "alguém que se faz de amigo, mas na verdade é um traidor". O termo "chinelo" é definido como "uma pessoa que rouba alguma coisa de você e vende e depois nega, mesmo sabendo que roubou". Alguém que "deixa o outro na mão" é chamado de "arrombado". Nesse caso, "deixar o outro na mão" significa abandonar o companheiro em al guma situação. Para "aquele que se acha esperto" o termo usado é "malandro agulha". "Sequelado" é destinado para "alguém com distúrbio, mente parada". Convém ressaltar que, para o grupo, esse termo faz referência a usuários de drogas que possuem sequelas ocasionadas pela droga, tornando a pessoa com dificuldade de se relacionar, raciocinar ou compreender as coisas. "Baba ovo" ou "puxa saco" referem-se a uma pessoa que conquista alguém para conseguir algum benefício em troca. Para referir-se a um policial militar foram usados os termos "porco" e "coxinha". A 


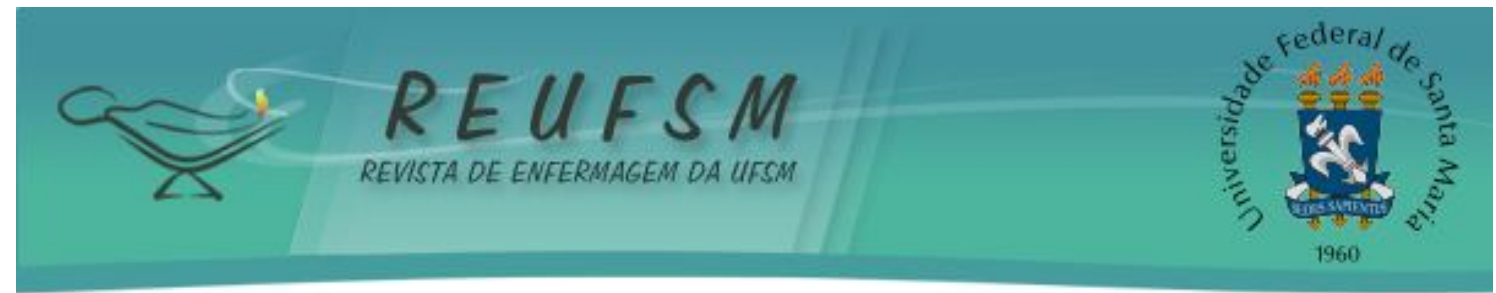

"pessoa forte" é chamada de "bombado", termo usado no sentido pejorativo por acreditar-se que a pessoa faça uso de anabolizantes também conhecidos como "bomba", é para ficar forte e adquirir músculos. "Gente boa" ou "sangue bom" são usados para designar a pessoa que tem bom caráter e é legal. "Brau" significa "um cantor de uma favela". "Bicudo" é alguém que "tá no osso, fica cuidando". "Look" significa que "não tá ligado na banda", refere-se a alguém que está desatento ao assunto. A gíria "mina" é utilizada para referir-se à mulher. O "canetinha" é aquele que "passa a bola entre as pernas dos outros", essa gíria citada pelos jovens também é comumente usada por jogadores de futebol, pois a "caneta" é um tipo de "drible" que é realizado nesse jogo. "Chorinho" é "quando pede alguma coisa", essa expressão é utilizada quando alguém faz muitas reclamações, uma vez que isso costuma acontecer frequentemente durante uma partida de futebol ou qualquer outro jogo.

Esses vocábulos são usados como identidade atribuída ou pressuposta, as quais se referem às características atribuídas aos indivíduos pelo grupo. Trata-se de uma identidade dada, atribuída, outorgada pelo outro e mediada por este. ${ }^{16}$ Tais gírias refletem a dimensão da criatividade desses adolescentes e percebe-se o quanto isso contribui para 0 conhecimento da identidade cultural e grupal dos mesmos, propiciando a troca de saberes onde, ao mesmo tempo em que ensinamos, também aprendemos a dialética. A interação profissional-usuário se dá pela compreensão do diferente, a valorização das singularidades humanas e a potencialização dos diferentes saberes; dessa forma, as interações de cuidado se expressam pela compreensão dialógica, criativa e dinâmica de suj eito-a-suj eito. ${ }^{17}$

\section{Expressão de sentimento}

"Tô legal", "sossegado", "sereno" e "tranquilo são gírias que dizem respeito ao estado humoral em que a pessoa se encontra em determinado momento. Nesse caso, indica que a pessoa está bem ou que está tudo certo, sem qualquer problema. A palavra "peita" está relacionada à camiseta. "Tá ligado" significa "sabe o que eu estou dizendo?". O termo "tá ligado" é frequentemente utilizado na comunicação entre esses adolescentes, para indagar se a pessoa entendeu o que foi dito. "Pode crê" significa obrigado, tal gíria, na visão desses jovens, refere-se à gratidão, forma de expressar agradecimento por algum favor ou uma ajuda. A expressão "molha tanga" significa "quando está a fim de alguém", referindo-se ao desej o que uma pessoa possui de se relacionar com alguém. 0 termo "sipá" significa "talvez", logo, é compreendida pelo grupo como expressão de dúvida.

Determinadas gírias também demonstram sentimentos bons ou ruins que os falantes querem expressar, ou até situações vivenciadas no dia a dia, como dúvida, gratidão, desejo entre outros. Também podemos observar que a linguagem usada na comunicação desses adolescentes é muito diversificada e rica em significado expandindo-se com certa facilidade entre o grupo e sendo de uso comum entre os pesquisados.

0 percurso semântico do vocábulo gírio mostra que ele se torna um recurso importante, principalmente para expressar sentimentos como crítica, ironia, ridículo, desprezo, humor. Na sua origem, os vocábulos gírios demonstram que existe uma forma de se relacionar a gíria com a visão que o falante expressa do mundo em que vive. ${ }^{18}$

\section{Termos dados a objetos e situações}

Tanto "xarope" quanto "massudo", possuem o mesmo significado, referindo-se a algo muito legal, muito bom. Para o grupo "dar uma banda" quer dizer "dar uma volta". "Baia" é uma gíria utilizada para designar casa, lar, moradia. "Baixar", segundo os adolescentes, quer dizer "matar alguém e sair fugido", ou seja, realizar um homicídio. 


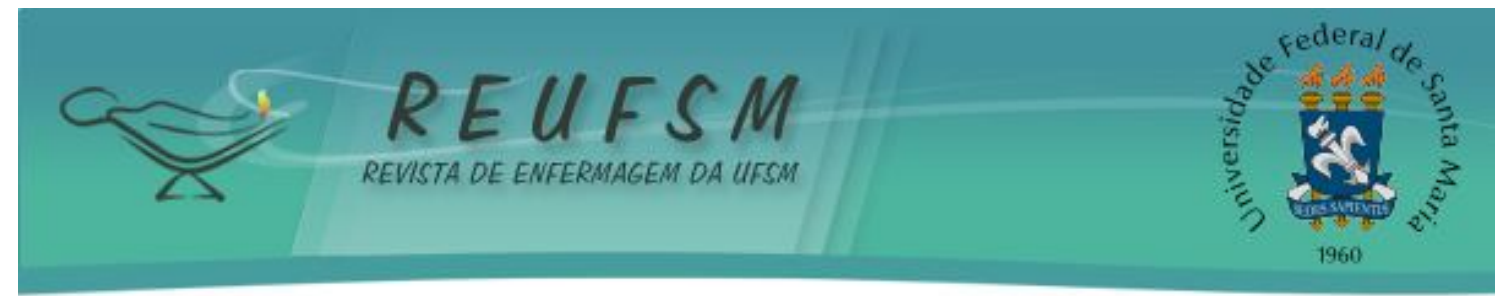

"Largar no pinote", "sumi na neblina" e "largar correndo", são expressões que se referem à fuga de algum lugar, sair rápido de alguma situação. "Dá uns pega e não se apega", "dá uns pega na mina" e "ficar", são gírias que fazem referência á uma relação amorosa ocasional, passageira, sem o envolvimento emocional ou sentimental com a outra pessoa. "Ficar campanado" sugere algo que é feito com o intuito de vigiar uma casa para um possível roubo. "Tá um boi" refere-se a algo fácil de fazer ou conseguir. A expressão "quais as condições?", refere-se a um "convite para namoro", expressando o desejo de uma união amorosa. "Te liga", "fica esperto" e "não viaja" servem como um alerta para que a pessoa fique atenta a alguma situação ou em algo que esta sendo falado. "Altos tri" indica algo "que é legal", é extraordinário. O termo "bita" na visão destes jovens refere-se à comida.

Observamos que o grupo realiza a transmissão de informações entre si de forma dinâmica e, muitas vezes, hostil, usando muita criatividade, irreverência e originalidade para criação de novos termos, tanto no cotidiano quanto no convívio social. Muitas vezes a gíria se identifica com o comportamento dos jovens, os quais muitas vezes são marcados pela insatisfação, rebeldia e pelo espírito de irreverência. Assim, a juventude constrói formas próprias de existência, para comunicar-se de forma mais dinâmica e explosiva. ${ }^{4}$

\section{Codinomes dados às Substâncias Psicoativas (SPA)}

Algumas palavras são usadas em referência às drogas, as quais são substituídas pelos nomes convencionais das substâncias psicoativas, sendo uma espécie de apelido atribuído à droga. Dentre elas encontramos: "Criptonita" que refere-se ao crack, a criptonita é uma pedra preciosa e é relacionada ao crack, pois este também apresenta-se na forma de uma pedra. Essa mesma droga também é conhecida no grupo como "drap" ou "cafezinho". Já a cocaína é chamada de "pó", ela possui esse significado por apresentar-se na forma de um pó branco. "Crivo" é o termo utilizado para referir-se ao cigarro, dessa forma, a expressão "me dá um crivo" é usada para pedir cigarro à outra pessoa. A gíria "chá de cogumelo" também se refere às drogas e está relacionada ao próprio chá de cogumelo que é uma substância psicoativa, a qual é obtida através da extração de fungos alucinógenos. Já a palavra "bagulho" pode ser entendida como droga ou como um objeto qualquer, dependendo do momento onde a gíria está sendo empregada e das expressões corporais utilizadas durante o diálogo.

Podemos perceber que essas gírias são específicas de usuários de substâncias psicoativas e só membros do grupo conseguem decodificar seu significado, tornando-se uma espécie de código entre eles, por isso é chamada de gíria de grupo.

A gíria de grupo é específica de cada grupo e está relacionada a classes pouco cultas. Funciona como um código secreto entre os membros de um determinado grupo, isto é, a de um vocabulário de grupos sociais restritos. ${ }^{19}$

\section{Termos originários do código penal}

Alguns termos utilizados pelo grupo têm suas origens no Código Penal Brasileiro. Na visão desses jovens a gíria "157" significa "ladrão". A sua origem decorre do artigo identificado com o mesmo número. Segundo este, o roubo é caracterizado como subtração de coisa móvel alheia. Já "Duk 13" advém do artigo 213 o qual define o crime de estupro e, portanto estuprador. "Duk", na linguagem do grupo significa dois. Além disto, a gíria "171", originada do artigo com o mesmo número (caracteriza omissão) é usada para designar alguém mentiroso.

Alguns termos utilizados pelos adolescentes são originários de uma língua comumente 'falada'. Logo, podem ter sua composição léxica, morfológica e fonética 


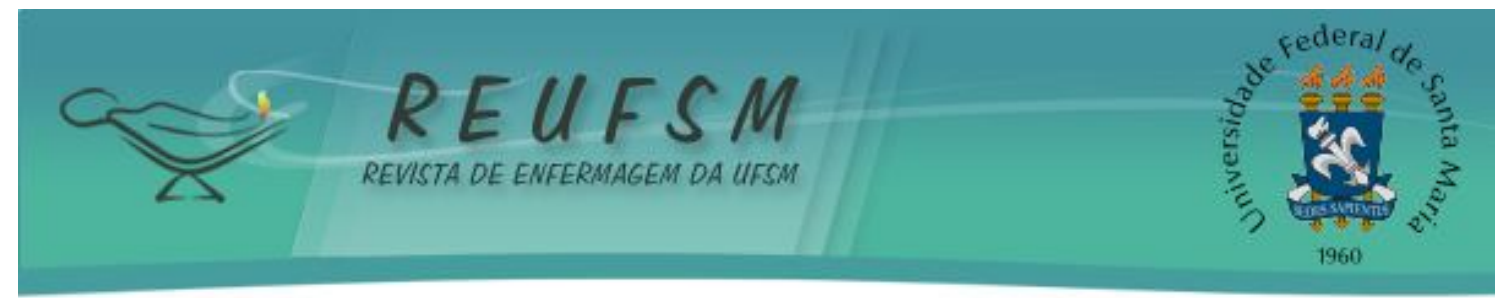

parecidas, assim como observamos nas gírias acima que possuem semelhanças com as infrações do Código Penal Brasileiro.

Os processos de formação de gíria estão embasados nos de sua língua de origem, pois é considerada uma forma parasitária da língua comum, ligando como principal fonte a fonética, a morfologia e o léxico. ${ }^{20}$

Durante a coleta de dados, não analisamos somente a comunicação verbal emitida pelos pesquisados pois, além desta, é necessário que venhamos a compreender a comunicação não verbal apresentada pelo grupo durante o diálogo para que, então, possamos perceber o contexto em que a gíria se encontra. Isso se deve ao fato de que uma mesma palavra pode ter múltiplos significados como raiva, euforia ou humor dependendo da situação em que os falantes se encontram, bem como das expressões emitidas pelo corpo.

A comunicação não verbal foi observada através dos gestos, risadas, maneirices, engasgos e pela forma de olhar, os quais se fizeram presentes durante o diálogo com os adolescentes. Sendo assim, sua decodificação foi imprescindível para que pudéssemos entender o que realmente se pretendia dizer através de cada fala.

"Os gestos e os movimentos fazem parte dos recursos de comunicação que o ser humano utiliza para expressar suas emoções e sua personalidade, comunicar atitudes interpessoalmente e transmitir informações. " ${ }^{3}$

Os jovens, usam uma linguagem criativa se comunicarem, a gíria. Essa linguagem popular contém termos próprios que possuem um sentido literal e outro sentido figurado, no qual este último será definido através da observação de seu uso nos determinados contextos. ${ }^{21}$

\section{CONSIDERAÇÕES FINAIS}

Percebe-se o quanto o universo do adolescente é rico em imaginação, porém sua linguagem é pobre, permitindo que uma única palavra tenha vários significados, mostrando que os profissionais devem estar sempre atentos para conseguir acompanhar e compreender 0 contexto geral do assunto. Atribuímos isso à pobreza de leitura e a falta de estímulo no meio em que vivem para o desenvolvimento das suas potencialidades.

Observa-se que determinadas gírias utilizadas por este grupo são muito específicas e pouco conhecidas pelos profissionais de saúde por serem de uso restrito entre um determinado grupo, como é 0 caso dos codinomes dados às substâncias psicoativas e dos termos originários do código penal.

Muitas das gírias usadas para designação de pessoa, expressão de sentimento e termos dados a objetos e situações, tornam-se de certa forma familiares e de fácil compreensão, pois estas são utilizadas com maior freqüência tanto pelos usuários de SPA como pelos demais adolescentes.

O uso da gíria facilita a aproximação entre esses jovens e a interação entre eles, fazendo com que a identidade grupal de ambos sej a facilmente reconhecida.

Este tipo de linguagem sempre está em constante evolução, apesar de ser usada por todas as faixas etárias, seus principais usuários são os adolescentes que, em sua maioria, fazem a escolha de seus grupos de convívio por meio da afinidade entre os membros e, dessa forma, passam a criar sua própria identidade cultural.

A comunicação não verbal mostrou-se de grande relevância para que pudéssemos melhorar nossa compreensão sobre as palavras usadas pelo grupo, pois através de cada gesto feito com as mãos, com o olhar, com a expressão facial e com a postura é que identificamos realmente qual o sentimento que passava por trás das expressões utilizadas.

Acreditamos que sem a comunicação não verbal não é possível decodificarmos por completo os significados expressos pelas falas do grupo, pois são as expressões corporais que nos dão a compreensão legítima do contexto onde está inserida cada uma das falas, sendo indissociável a compreensão da linguagem verbal de forma isolada. 


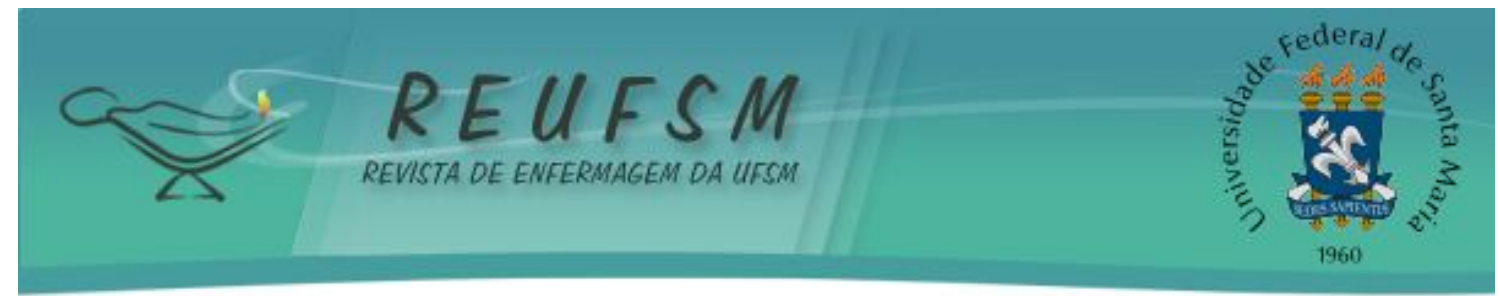

Com este estudo podemos entender melhor a comunicação usada entre os adolescentes em seu cotidiano. Sendo notável sua contribuição para melhorar a interação entre profissional e sujeito e, consequentemente, obter maior adesão às estratégias de saúde desenvolvidas pare esta população. Em síntese, através da linguagem é possível propiciar o enriquecimento de ambos e, para tanto, é necessária que esta seja feita de forma dialética na qual todos possam ensinar e também aprender através do processo comunicativo.

Novas pesquisas nesta área, ampliadas a outros adolescentes incluindo não usuários de SPA, devem ser fomentadas pois certamente contribuirão para o cuidado da enfermagem na saúde do adolescente.

\section{REFERÊNCIAS}

1. Ministério da Saúde (BR). Conselho Nacional de Saúde. Diretrizes e normas regulamentadoras de pesquisa envolvendo seres humanos. Resolução n. 196, de 10 de outubro de 1996. Brasília; 1996. [acessado em 10 mar. 2010]. Disponível em: 〈http://www.usjt.br>.

2. Brasil. Ministério da Saúde (BR), Estatuto da Criança e do Adolescente. Lei 8.069/90, de 13 de Julho de 1990. [Internet] Brasília (DF). [acessado em 10 mar. 2010]. Disponível em: বttp:// portal. mec. gov. br>.

3. Matthiesen S, Darido SC, Lorenzetto LA, lório LS, Rangel ICA, Rodrigues LR et al. Revista Mackenzie de Educação Física e Esporte [periódico na internet]. 2008 [acessado em 05 mar 2010];7(2). Disponível em: http:// www3. mackenzie.br>.

4. Alvarez MLOA. A gíria juvenil em três contextos latino-americanos: Cuba, Brasil e Chile. Revista Contextos (Santiago de Chile) [periódico na internet], 2007 [acessado em 05 mar 2010];(1):21-38. Disponível em: 〈http:// www. let. unb. br>.

5. Bezerra MA, Maior ACS, Barros ACS. A gíria: do registro coloquial ao registro formal. Cadernos do IV Congresso Nacional de Linguística e folologia [internet], v.3. Rio de J aneiro. [acessado em 05 mar 2010]. Disponível em: 〈http:// www. filologia.org.br>.

6. Remenche MLR. Diferenças Regionais na Giria do Sistema Penitenciário. [acessado em 27 mar 2010]. Disponível em: «ttp:// www. buscalegis.ccj.ufsc.br>.

7. Silva AF da. Gíria: linguagem ou vocabulário?. Revista Philologus [periódico na internet], 2008 [acessado em 10 mar 2010];14(41). Disponível em: বhttp:// www. filologia.org. br>.

8. Schoen-Ferreira TH, Aznar-Farias M, Silvares EFM. A construção da identidade em adolescentes: um estudo exploratório. Estud psicol (Natal) [periódico na internet]. 2003 [acessado em 27 jul 2010]; 8(1):107-115. Disponível em: http: / / www. scielo.br/ scielo. php?script =sci_arttext\&pid $=$ S1413-

$294 \times 2003000100012 \&$ lng $=$ pt\&nrm=ंso\&tlng=pt

9. Souza MV. Globalização e revalorização da identidade cultural. [acessado em 21 mar. 2010]. Disponível em: বhttp:// www.sbec.org.br>.

10. Brasil. Resolução no 101, de 30 de maio de 2001. Normas mínimas para o funcionamento de serviços de atenção a pessoas com transtornos decorrentes do uso ou abuso de substâncias psicoativas, segundo modelo psicossocial, também conhecidos como Comunidades Terapêuticas. Brasília: Agência Nacional de Vigilância Sanitária (ANVISA); 2001. [acessado em 10 mar 2010]. Disponível em: 〈http:// www.anvisa.gov.br>. 


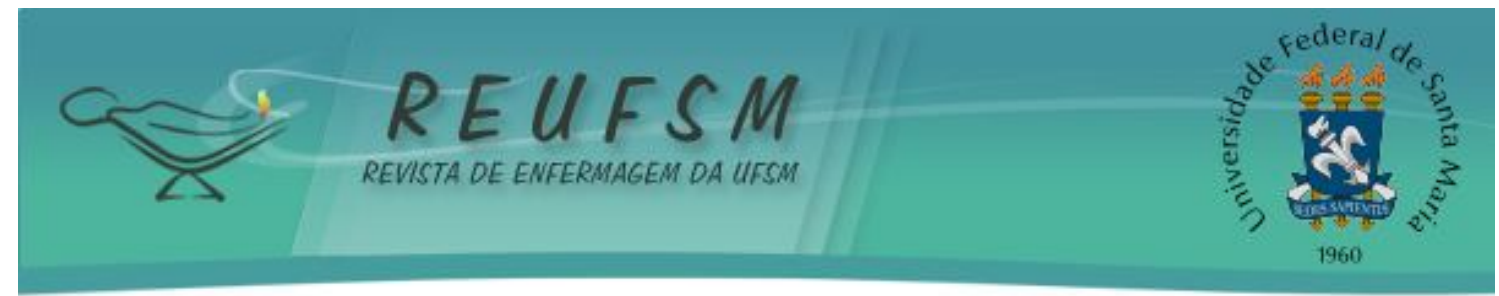

11. Turato ER. Métodos qualitativos e quantitativos na areada saúde: definições, diferenças e seus objetos de pesquisa. Rev saúde pública [periódico na internet]. 2005 [acessado em 10 mar 2010];39(3):507-14. Disponível em: http:/ / www. scielosp.org/ scielo. php?script=sci_arttext\&pid=S0034-

89102005000300025\&lng=en. http:// dx. doi. org/ 10.1590/ S0034-89102005000300025.

12. Silva EL, Menezes EM. Metodologia da Pesquisa e Elaboração de Dissertação. Florianópolis: Universidade Federal de Santa Catarina Programa de Pós-Graduação em Engenharia de Produção Laboratório de Ensino a Distância. [acessado em 25 jul 2010]; 2001. Disponível em: «ttp:// projetos.inf.ufsc. br>.

13. Lervolino SA, Pelicioni MCF. A utilização do grupo focal como metodologia qualitativa na promoção da saúde. Rev Esc Enferm USP. 2001;35(2):115-21.

14. Queiroz DT, Vall J, Souza AMA, Vieira NFC. Observação Participante na Pesquisa Qualitativa: Conceitos e Aplicações na Área da Saúde. R enferm UERJ . 2007; 15(2):276-83.

15. Minayo MCS. O desafio do conhecimento: pesquisa qualitativa em saúde. 2a ed. São Paulo: Ed. Hucitec-ABRASCO; 1993.

16. Ciampa AC. A identidade social e suas relações com a ideologia. São Paulo : [s.n. ], 1977. 147 p. Dissertação (Mestrado em Psicologia Social) - Faculdade de Psicologia, PUC-SP, 1977.

17. Moreschi C, Siqueira DF, Piexak DR, Freitas PH, Rangel RF, Morisso T da S, Backes DS. Interação profissional-usuário: apreensão do ser humano como um ser singular e multidimensional. R Enferm UFSM [periódico na internet]. 2011 [acessado em 15 jan 2011]; 1(2):225-237. Disponível em: http:// cascavel. ufsm. br/ revistas/ ojs2.2.2/ index. php/ reufsm/ article/ view/ 2086/ 1508.

18. Preti D. O Léxico na Linguagem Popular: A Gíria. [acessado em 05 mar 2011]. Disponível em: বttp:// www.fflch.usp.br>.

19. Preti D. Estudos de língua oral e escrita. Rio de J aneiro: Lucerna; 2004.

20. Preti D. Um pesquisador pioneiro, premiado e... coisa inédita nos meios acadêmicos... muito humilde. Entrevista concedida a Renira Cirelli Appa na Faculdade de Filosofia, Ciências e Letras da USP, em 15 de março de 2005. [acessado em 21 fev 2011]. Disponível em: বhttp:// www. letramagna.com>.

21. Araujo ACM. Linguagem dos J ovens: Contexto e Significados. Publicado em 14 set 2010. [acessado em 05 mar 2011]. Disponível em: http:// www.artigonal.com/linguas-artigos/alinguagem-dos-j ovens-contexto-e-significados-3261845. html .

Data de recebimento: $11 / 08 / 2011$

Data de aceite: 24/09/2011

Contato com autor responsável: Zaléia Prado de Brum

Endereço: Rua Samuel Morse n53, apto 203, Bairro Dornelles, Santo Ângelo, RS.

E-mail: zaleia@urisan.tche.br 